\title{
EXPERIENCE OF SIGNIFICANT LIFE EVENTS IN INDIVIDUALS DIAGNOSED WITH PREHYPER- TENSION
}

\author{
Ivanka Boncheva ${ }^{1}$, Aneta Misheva ${ }^{2}$ \\ 1) Department of Psychiatry and medical psychology, Medical University - Varna \\ 2) Specialized Hospital for Active Treatment in Cardiology, Veliko Tarnovo
}

\begin{abstract}
:
The paper presents results of investigation of life significant events experience, in individuals diagnosed with prehypertension to prove the connection between the individual significance level of each event and elevation of blood pressure, compared with people of the same age groups, but without elevated blood pressure. The table of Holmes and Rahe (1967) for significant life events has been used in order to prove this assertion. The results show that patients with prehypertension went through significant life events during the last five years and have emotional charge with double strength compared to those with normal blood pressure. They insist on functioning at an optimal level of their physical and psychic energy and experience every change stressfully even in the positive emotional aspect.
\end{abstract}

Key words: prehypertension, vitally important events, experience, stress

The term ,prehypertension” was introduced as a new risk category in the Seventh Report of the Joint National committee on High Blood Pressure in 2003. The condition is characterized by blood pressure of $120-139 / 80-89 \mathrm{~mm} \mathrm{Hg}$. The introduction of the term aims to focus on the need for changes in lifestyle before the blood pressure values are defined as hypertension [1]. The prehypertension conditions are subject of increased scientific interest at present in order to derive reliable prognostic markers and appropriate strategies for prevention, treatment and monitoring of the global cardiovascular risk [2]. Scientists proceed on the grounds of collected files about the increased risk for chronic kidney disease (CKD) in individuals with prehypertension. It was also pointed out the relation between insulin resistance and hypertension - respectively the metabolic syndrome (MS).

Recent data from two major studies suggest that high levels of anger line are associated with increased risk of incident stroke among younger people and those with higher levels of HDL cholesterol [3], and that high levels of anger line compared to low and medium levels in middleaged men with prehypertension were connected with increased risk of developing hypertension and incidents of coronary heart disease.

Long-term psychological stress is associated with increased risk of incidence coronary heart disease both in men and women $[4,5]$.

The aim of our study is to find out the extent, frequency and content of experiencing significant life events in individuals with prehypertension.

\section{MATERIALS AND METHODS}

The study has been done in individuals of young age (according to WHO criteria) from 19 to 44, divided into two main age subgroups from 19 to 29 and from 30 to 44 .

a/ Group A- age 19 to $29: 15$ women and 15 men with prehypertension

b/ Group B-healthy individuals of the same age: 12 women and 11 men

c/ Group A№ - age 30 to $44: 15$ women and 15 men with prehypertension

d/ Group B № - healthy individuals of the same age: 13 women and 3 men

It covers a total of 99 people, men and women (60 of them with prehypertension and 39 with normal blood pressure). Prehypertension as a condition is stated by a physician.

For the study of life significant events is used the table of Holmes and Rahe [6]. It has three subscales: "Private life" = 22 statements; "Family" = 13 statements; "Work" $=8$ statements. The results are processed on the basis of the reflected degree of importance of event experience - from 1 (minor) to 3 (of high importance). The evaluation period of experienced events is five years back.

\section{RESULTS}

Comparing the group of people with prehipertension and those with normal blood pressure suggests the following features: 
Table 1. Frequency of life significant events.

\begin{tabular}{|l|c|c|c|c|c|c|c|c|}
\hline \multirow{2}{*}{$\begin{array}{l}\text { Factors/ Subscales, } \\
\text { expressed in } \\
\text { percentages }\end{array}$} & \multicolumn{3}{|c|}{ Individuals with prehypertension } & \multicolumn{4}{c|}{ Healthy individuals } \\
\cline { 2 - 9 } & \multicolumn{2}{|c|}{ Age 19-29 } & \multicolumn{2}{|c|}{ Age 30-44 } & \multicolumn{2}{c|}{ Age 19-29 } & \multicolumn{2}{c|}{ Age 30-44 } \\
\cline { 2 - 9 } & Female & Male & Female & Male & Female & Male & Female & Male \\
\hline $\begin{array}{l}\text { Total number of } \\
\text { events experienced }\end{array}$ & 39,89 & 69,92 & 82,75 & 63,78 & 62,1 & 54,93 & 64,01 & 15,44 \\
\hline „Private life” & 59,09 & 63,63 & 63,63 & 59,09 & 45,45 & 59,09 & 63,63 & 13,63 \\
\hline „Family” & 23,08 & 46,15 & 84,62 & 53,84 & 40,9 & 18,2 & 40,9 & 7,69 \\
\hline „Work” & 37,50 & 100 & 100 & 87,5 & 100 & 87,5 & 87,5 & 25 \\
\hline
\end{tabular}

Both groups age 19-29, have a lot of life significant events. There is a statistically significant difference between women with hypertension from both of the groups $(p<0,01)$, and also between women with prehypertension and healthy individuals. Only women with prehypertension share a small number of significant life events. Gender-specific in both groups women experience more life significant events compared to men and report them as such. Within the frame of subscale „Private life”(events that have already occurred because of personal preferences and aspirations of individuals) more events, experienced with greater force are these with prehypertension - average of $64 \%$; in healthy individuals $-45 \%$ from all events in the scale $(p<0,05)$. In extremely high percentage of healthy individuals and those with prehypertension experience is the experience of significance in subscale „Work”. Subscale „Family” is mostly expressed in women with prehypertension in the upper age group.

Healthy people have approximately similar number of events to those with prehypertension. With a trend towards statistical significance is the ease of experiencing the events by healthy individuals, driven by their personality characteristics - subscale "Private life". There is a similar trend in subscale „Family” as well. Both treatment groups experience the events with equal importance in subscale "Work".

Ranging the most significant statements on the scale of Holmes and Rahe showed the following data. From 44 events the respondents indicated 11 as the most significant.

Table 2. Contents of highest importance.

\begin{tabular}{|c|c|c|c|c|c|c|c|c|}
\hline \multirow{3}{*}{$\begin{array}{l}\text { Factors expressed } \\
\text { in percentages }\end{array}$} & \multicolumn{4}{|c|}{ Individuals with prehypertension } & \multicolumn{4}{|c|}{ Healthy individuals } \\
\hline & \multicolumn{2}{|c|}{ Age 19-29 } & \multicolumn{2}{|c|}{ Age 30-44 } & \multicolumn{2}{|c|}{ Age 19-29 } & \multicolumn{2}{|c|}{ Age 30-44 } \\
\hline & $\mathbf{F}$ & $\mathbf{M}$ & $\mathbf{F}$ & M & $\mathbf{F}$ & $\mathbf{M}$ & $\mathbf{F}$ & $\mathbf{M}$ \\
\hline Divorce & $\mathrm{X}$ & & & & & & & \\
\hline Personal misconduct & & $\mathrm{X}$ & & & & & & \\
\hline Family member illness & & & $\mathrm{X}$ & $\mathrm{X}$ & & & & \\
\hline Change of eating habits & & & & & & $\mathrm{X}$ & & $\mathrm{X}$ \\
\hline Income change & $\mathrm{X}$ & $\mathrm{X}$ & $\mathrm{X}$ & $\mathrm{X}$ & & & & \\
\hline Personal decisions for change & $\mathrm{X}$ & $\mathrm{X}$ & & & & & & \\
\hline Standard of living change & $\mathrm{X}$ & $\mathrm{X}$ & $\mathrm{X}$ & $\mathrm{X}$ & & & & \\
\hline Physical functioning & $\mathrm{X}$ & $\mathrm{X}$ & $\mathrm{X}$ & $\mathrm{X}$ & $\mathrm{X}$ & $\mathrm{X}$ & $\mathrm{X}$ & $\mathrm{X}$ \\
\hline Workplace change & & & & & & & $\mathrm{X}$ & \\
\hline Holidays & $\mathrm{X}$ & $\mathrm{X}$ & & & & & & \\
\hline
\end{tabular}

Patients with prehypertension have emotional charge with double strength when they experience events of vital importance which happened in the last 5 years' of time, compared to those with normal blood pressure. In the first group with prehypertension (age 19-29, men and women) all kind of personal changes are very stressful experience (new level of activities; home, financial status), and also events in positive aspect (holidays). In both groups there has been an emotional fixation on the optimal physical and physiological functioning(sleep, nutrition, weight). Younger individuals experience the second most important need to succeed in their personal initiatives.

In the second age group (age 30-44) of prehypertension, there is a distinct increasing of the degree of importance for events, directly arising from personality characteristics and acquiring of coping strategies. Equally painful men and women experience dramatic change in their own or family member's health condition (other disease 
outside the presence of prehypertension), and the failure of one decision making.

In healthy young women life significant events are much more than in young individuals with prehypertension but they don't have so painful experience.

In healthy young men compared to those with prehypertension fewer significant life events are found.

\section{CONCLUSION}

Individuals with prehypertension keep functioning at an optimal level of using their physical and mental forces mainly in events that they experience as his own decision for change. This is more important for younger people with prehypertension. The presence of an effect that differs from the desired one or failure is very stressful for them, with a high degree of significance. In the younger group is very stressful even the event in positive emotional aspect.

Although there is no significant difference in the total number of experienced events for healthy and sick people, those with prehypertension suffer much more in objectively occurring events than the healthy individuals. In the second age group of individuals with prehypertension (age 30-44), increases the degree of importance for events arising directly from the personality characteristics and acquired coping strategies. It can be seen the emotional fixation in negative sthenic aspect - discontent, a desire to defend the old.

Healthy people in this group tend to make personal changes for new consolidation of their forces (eating habits; change of activity) and don't experience it so stressfully.

The following picture has been created for individuals with prehypertension:

a/ Age 19-29 - of ,decisive and ambitious young people", willing to set their own events around them and rely on the priority of their own personal qualities than on working with others. When events happen that are out of their control this can certainly be a challenge to their psychophysical condition.

b/ Age 30-44 - of ,rigid, unhappy people”, suffering painfully from the events beyond their control; in fact suffering much more from inertia of assessment and the use of probably identical and inflexible coping strategies.

Both pictures present for discussion the hypothesis of personality predisposition of individuals with prehypertension in their way of experiencing. The root cause is probably the need to constantly feed a high level of selfesteem at the expense of their personal strengths and abilities.

It can be assumed that people with prehypertension during adolescence trace the formation of personality characteristics described by many authors as type A 'hypertensive' personality.

\section{REFERENCES:}

1. Qureshi AI, Suri MF, Kirmani JF, Divani AA, Mohammad Y. Is prehypertension a risk factor for cardiovascular diseases? Stroke. 2005 Sep;36(9):185963. [PubMed] [CrossRef]

2. Orbetzova M, Nikolov F. Metabolic syndrome and hypertension, Medinfo. 2011.

3. Williams J, Nieto FJ, Sanford CP,
Couper DJ, Tyroler HA. The Association Between Trait Anger and Incident Stroke Risk. The Atherosclerosis Risk in Communities (ARIC) Study. Stroke. 2002 Jan;33(1):13-19. [PubMed] [CrossRef]

4. Player MS, King DE, Mainous AG 3rd, Geesey ME. Psychosocial factors and progression from prehypertension to hypertension or coronary heart
disease(CHD). Ann Fam Med. 2007 SepOct;5(5):403-411. [PubMed] [CrossRef]

5. Wulsin L, Barsky AJ. Psyhiatric and Behavioral Aspects of Cardiovascular Disease. In: Braunwald's heart disease (eight edition), 2008

6. Holmes TH, Rahe RH. The social readjustment scale. JPSoR, 11, 1967, 312318.

\author{
Address for correspondence: \\ Assos. Prof. Ivanka Boncheva, PhD. \\ Department of Psychiatry and Medical Psychology, \\ Medical University - Varna, Bulgaria, \\ 1, Hr. Smirnenski Boul., 9010 Varna, Bulgaria, \\ Mobile: +359887 722581 \\ E-mail: ibontcheva@yahoo.com;
}

